\title{
Toxicity Testing of Fire Effluents in Japan: State of the Art Review
}

\author{
FUMIHARU SAITO \\ Testing Laboratory of Center for Better Living \\ 2 Tatehara, Oho-machi, Tsukuba-gun, Ibaraki-ken, Japan \\ SHYUITSU YUSA \\ Building Research Institute, Ministry of Construction \\ 1 Tatehara, Oho-machi, Tsukuba-gun, Ibaraki-ken, Japan
}

ABSTRACT

The present state of research on toxicities of fire effluents in Japan is described. This review centers on the status of a joint study project which has been under way in recent years, participated in by research institutions in the country. The research setup in the country, the method of applying conditions of actual fires to testing apperatus of laboratory scale, the role of $\mathrm{CO}_{2}$ mixed with pure gases, and the results of square wave exposure of fire effluents in a newly developed testing apparatus are described.

\section{INTRODUCTION}

Research in Japen on toxicities of fire effluents has been mainly carried out at universities and by national research institutes and testing facilities of varlous goverment ministries and agencies. Studies to be carried out at the research institutions of the ministries and agencies are based on the administrative needs of the individual government organs. Therefore, the concepts of toxicities of fire effluents of these research organizations differ in degree and are being studied by means of different techniques. The Science and Technology Agency of the Japanese government has set up a system for allocating funds, taking up cases of joint studies by a plural number of research institutions as special research projects. A 5-years joint research program concerning toxicities of fire effluents was started 3 years ago with the cooperation of the United States and Canada (hereafter called "Project Research") under this budgeting system. In Japan, five nationaI research organs, two universities, and one public testing organ are cooperating end shaxing in the research work. This research is being done by the three working groups on establishment of burning conditions, development of testing apparatus, and development of an evaluation method, with three or four institutions participating in each working group. This is the first time that such a research organization has been set up in the field of fire safety science. So far, satisfactory results have been obtained. Here, the studies in Japan in recent years of toxicities of fire effluents will be described including the abovementioned results.

\section{BURNING CONDITIONS WHEN EVALUATING COMBUSTION TOXICTTY}

The comosition of gas emitted during combustion of a material is affected by burning conditions such as heating temperature, partial pressure of oxygen, ano configuration of the combustion chamber, and by the size and orientation of the sample. Consequentiy, it is clear that the potential for toxicity of effluents 


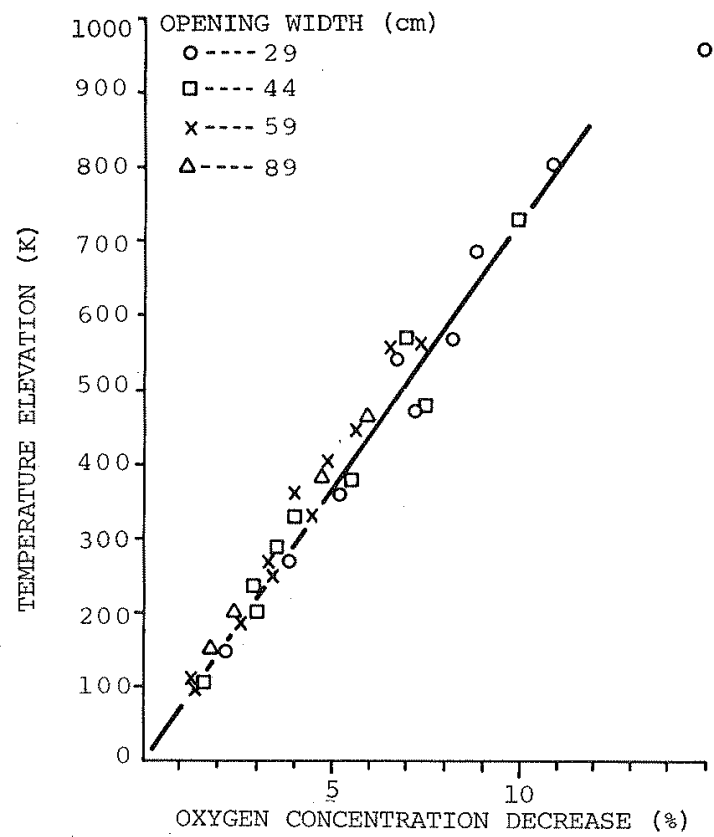

FIGURE 1. Relationship between the temperature rise and the oxygen concentration in the burn room (I).

in an actual fire varies depending on conditions and factors such as the space in the building, configurations and sizes of openings, and the quantities and shapes of combustibles. It is required that for toxicity testing of fire effluents these conditions and factors are reproducible on a laboratory scale. However, since it is difficult from the standpoint of manpower and cost to carry out these studies on a routine basis, the individual researchers have up to now arbitrarily set up only one or at most a few conditions of fire in testing. And it had not been made very clear whether these conditions simulated actual fires. In Project Research, with regard to heating conditions to which materials may be subjected during actual fires, a series of full scale steedy state fire experiments were conducted with a propane burner as the fire source in a burn room (3.45 x $3.55 \times 2.17$ meters) and a strong correlation has been recognized between temperature and oxygen concentration of the atmosphere as show in Fig. I (1). As a result, it is beginning to be shown that this correlation is useful as an aid in removing unreasonable test conditions in case of applying combinations of the two to toxicity tests.

\section{EVALUATIONT}

Test Animals

During a fire, a reduction in $\mathrm{O}_{2}$ concentration occurs along with generation of $\mathrm{CO}_{2}$ and $\mathrm{CO}$; possibly along with gases such as HCN, $\mathrm{HCl}$, and acrolein, depending on the chemical composition of the material burning. The mechanism and tolerance when any of these gases acts on the human body are specific to each individual gas, but during a fire the condition is that a plural number of these component gases are 
normally mixed together, and it will be necessary to evaluate the toxicity of fire effluents as the comprehensive effect of these mixed gases. In this case, the factors to cause impediments to oxygen supply capacities of bronchi, lungs, and blood of the human body differ depending on the component gas, and it is highly questionable whether the toxicity of the mixed gas can be considered to be the sum of the toxicities of the individual component gases. In order to clarify this point it will be necessary to use test animals, but this will again be accompanied by problems such as the correlation between test animals and human beings, and errors in evaluations using animals. To obtain correlation with human beings it is necessary to use primates as the test animals, but in Japan at present, mice are generally used from the fact that many mice can be tested at once and from the standpoints of cost, and ease of handling. The rotary cage method using mice has been adopted for Project Research, also.

\section{Studies Using Pure Gases}

When attempting toxicity evaluations based on chemical analysis values of fire effluents, it is first necessary to ascertain their actions exposing animals to pure gases. In the past, studies in Japan had been based on mortality of mice (2), but in Project Research, mice in rotary cages are exposed to pure gases of $\mathrm{Co}$, $\mathrm{CO} 2$, $\mathrm{NH}_{3}, \mathrm{NO}_{2}, \mathrm{HCl}$, and $\mathrm{HCN}$ individually and in mixtures, and toxicities of vaxious mixtures of the gases are evaluated based on incapaciation of the mice(3). Fig. 2 shows the results in separate exposures to the individual component gases. Here, the relationship between gas concentration at which mice are incapaciated in 5 to 30 minutes and time to incapaciation is expressed by the following equation:

$D=\frac{a}{T}+b$

where, D: gas concentration (\% or ppm)

$\mathrm{T}$ : time to incapacitation of mice

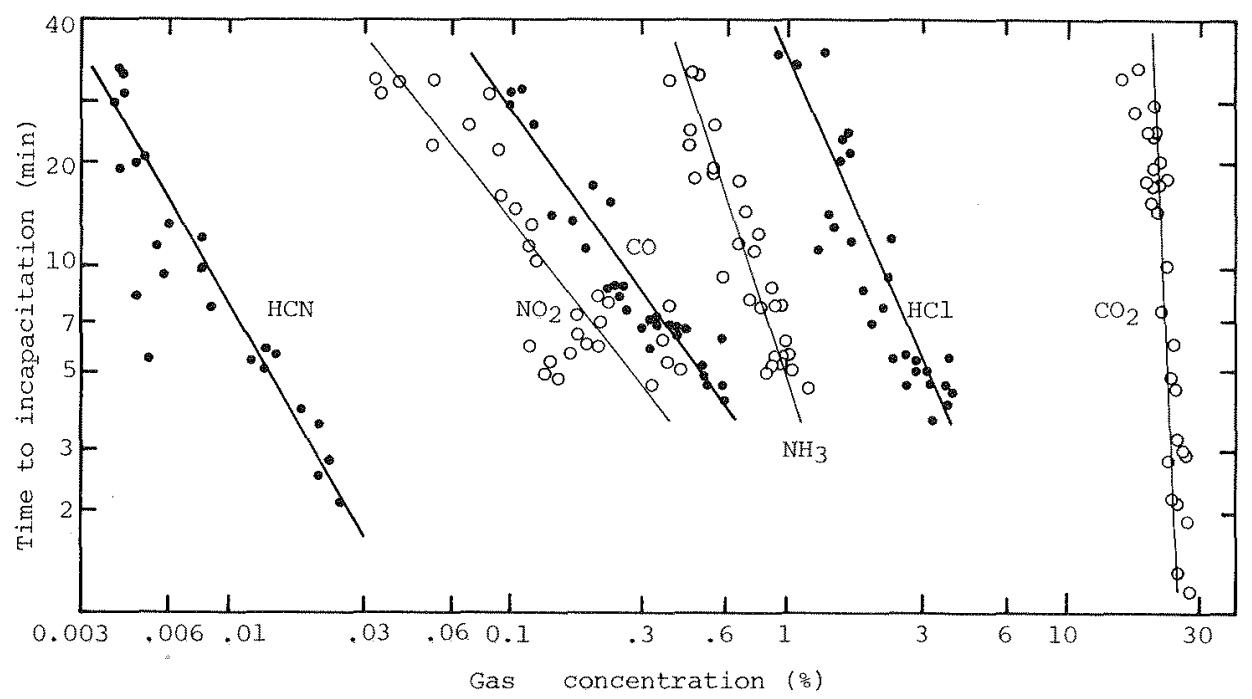

FIGURE 2. Incapacitation data for single gas. 
a, b: constant specific to the gas

The constants ' $a$ ' and ' $b$ ' in equation (1) were determined using the method of least squares. The values of constants in the study are shown in Table 1 . The regression lines for the relationships between the incapacitation times and the gas concentration are shown in Fig. 2 .

In the discussion of mixed gases, a non-dimensional gas concentration index $(\mathrm{Ig})$, which is defined by the following equation, was used.

$I g=\frac{D m-b}{D_{5}-b}$

where, Dm: measured gas concentration

$D_{5}$ : gas concentration corresponding to five minutes of incapacitation of mice in equation (1)

$b$ : constant in equation (1)

Fig. 3 shows the results of mixed gases using the gas concentration indexes. The curves in Fig. 3 are ideal ones $(I g=5 / T$ ) which correspond an additive effect between the individual gas. With regard to mixed gases, antagonism were seen in gases of $\mathrm{CO}$ mixed with $\mathrm{NH}_{3}$, and $\mathrm{HCl}$ while with a mixed gas of $\mathrm{CO}$ and HCN, it was confirmed that there is an additive action. However, there was antagonism when co and HCN of low concentration were mixed. As for when $\mathrm{CO}_{2}$ was further added to a number of these mixed gases, complex actions were seen to occur. In effect, the three kinds of mixed gases containing $\mathrm{NH}_{3}$, HCI and HCN were recognized to have their toxicities increased when $\mathrm{CO}_{2}$ was added compared with mixed only with $\mathrm{Co}$. However, it may need further investigation for the influence of the mixture of individual gases below the asymptotic concentration b.

Heat and moisture are generated simultaneously with combustion gas during a fire, and therefore, an environment in which these factors are also added is produced in a fire. It may expected that the increase in temperature causes the volume of respiration to increase, and it is thought that the physiological action. of toxic gases is accelerated by an increase in the volume respiration. The results

TABLE 1. Calculated values of constants ' $\mathrm{a}$ ' and ' $\mathrm{b}$ '.

\begin{tabular}{|c|c|c|c|c|}
\hline Gas & a. & $\mathrm{b}$ & $o^{1}$ & Unit of D \\
\hline $\mathrm{co}$ & 2.34 & 0.016 & 0.037 & $\%$ \\
\hline $\mathrm{CO}_{2}$ & 9.97 & 20 & 1.12 & $\not \%$ \\
\hline $\mathrm{NH}_{3}$ & 3.15 & 0.378 & 0.064 & $\%$ \\
\hline $\mathrm{NO}_{2}$ & 1.14 & 0.029 & 0.053 & $\%$ \\
\hline $\mathrm{HCl}$ & 10.34 & 0.904 & 0.156 & $\%$ \\
\hline $\mathrm{HCN}$ & 491 & 25.3 & 13.8 & ppm \\
\hline
\end{tabular}

$I_{\sigma}=\sqrt{\sum(D m-D)^{2} / N}$ 

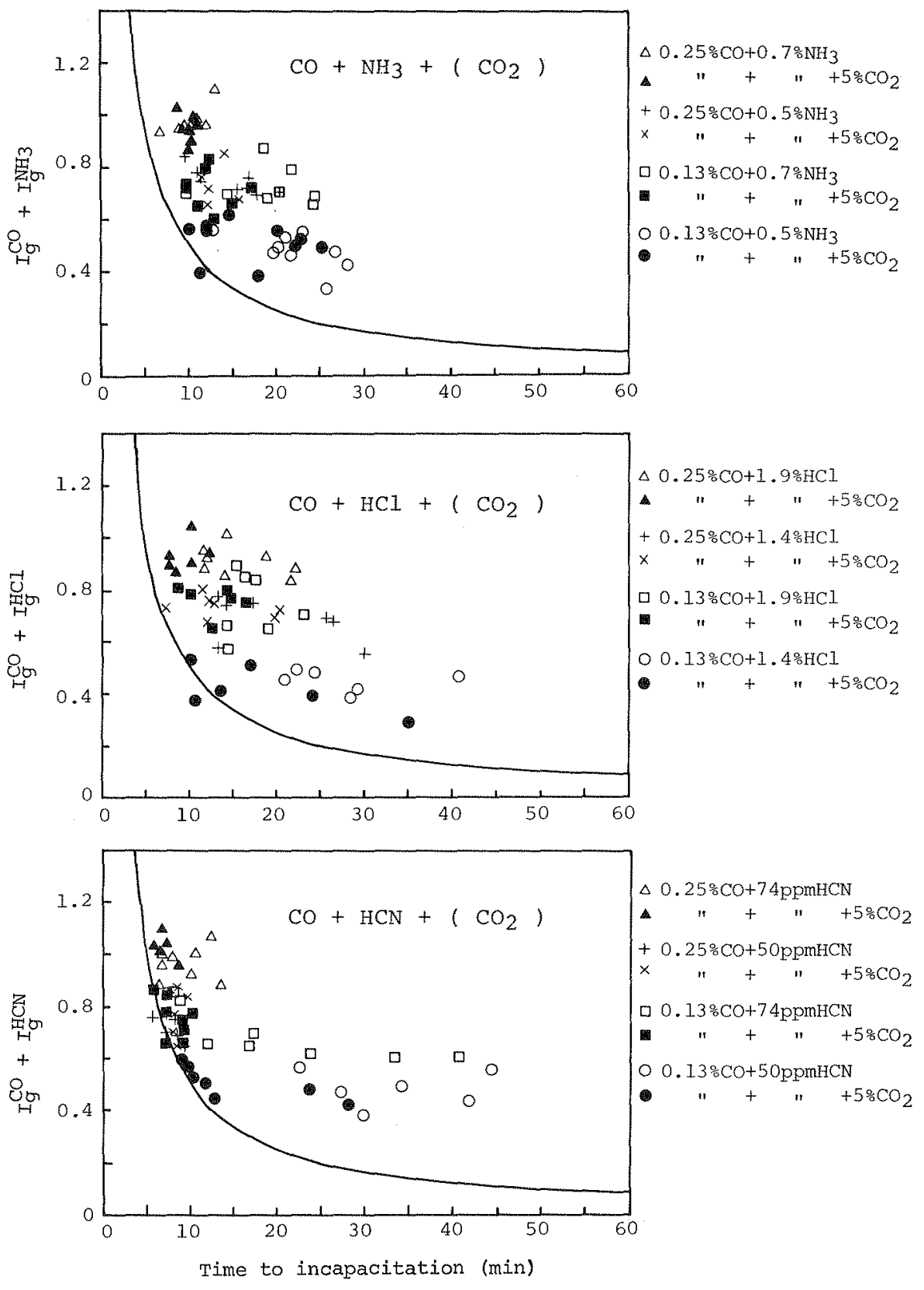

FIGURE 3. Relationship between the total gas concentration index and time to incapacitation of mice. 


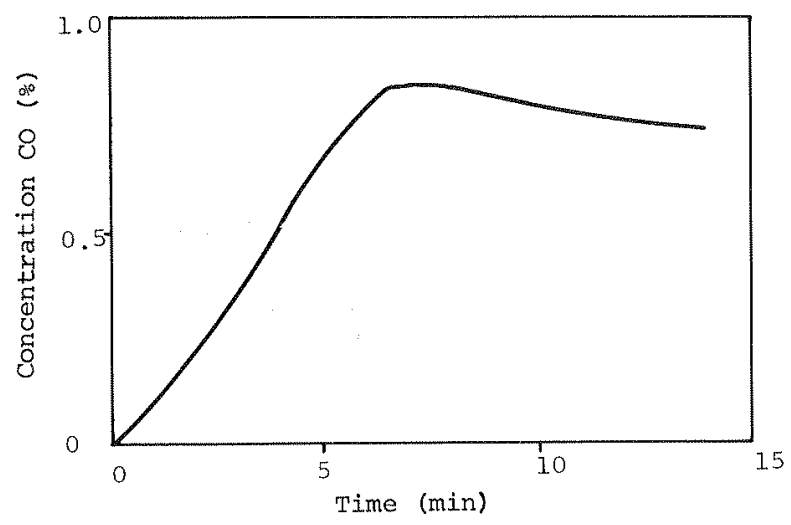

FIGURE 4. Co concentration in exposure chamber.

TABLE 2. Concentration time products for Co.

\begin{tabular}{|c|c|c|c|c|}
\hline \multirow{2}{*}{\multicolumn{2}{|c|}{ Temperature $\left({ }^{\circ} \mathrm{C}\right)$}} & \multicolumn{3}{|c|}{ humidity $(\not)$} \\
\hline & & 70 & 80 & 90 \\
\hline \multirow{3}{*}{30} & $\mathrm{Ct}^{2}$ & 3.45 & 2.82 & 2.67 \\
\hline & $s^{2}$ & 1.03 & 0.91 & 0.78 \\
\hline & $n^{3}$ & 22 & 27 & 40 \\
\hline \multirow{3}{*}{40} & $c t$ & 3.08 & 2.83 & 2.72 \\
\hline & $\mathrm{S}$ & 0.86 & 0.64 & 0.59 \\
\hline & $n$ & 60 & 43 & 39 \\
\hline \multirow{3}{*}{50} & $C t$ & 2.13 & 0.77 & 0.39 \\
\hline & $S$ & 0.58 & 0.35 & 0.15 \\
\hline & $\mathrm{n}$ & 30 & 38 & 30 \\
\hline
\end{tabular}

1 Average concentration time products for co

3 Standard deviation

Number of mice

of the experiments in which mice are exposed to some combinations of temperature and humidity under increasing co concentration (Fig. 4) are indicated in Table 2 which shows Concentration time products (ct) of co for incapacitation of mice. Although it is not clear whether the influence of humidity is significant or not, it seems that the temperature of $50^{\circ} \mathrm{C}$ affects greatly to incapacitation of mice.

There are cases when hydrophiric gases such as $\mathrm{NH}_{3}$ and HCl are contained in fire effluents, and although it is known that there are antagonisms between these gases in dry air, it will be necessary to study further regarding their biological effects when they exist in environments of high humidity. 


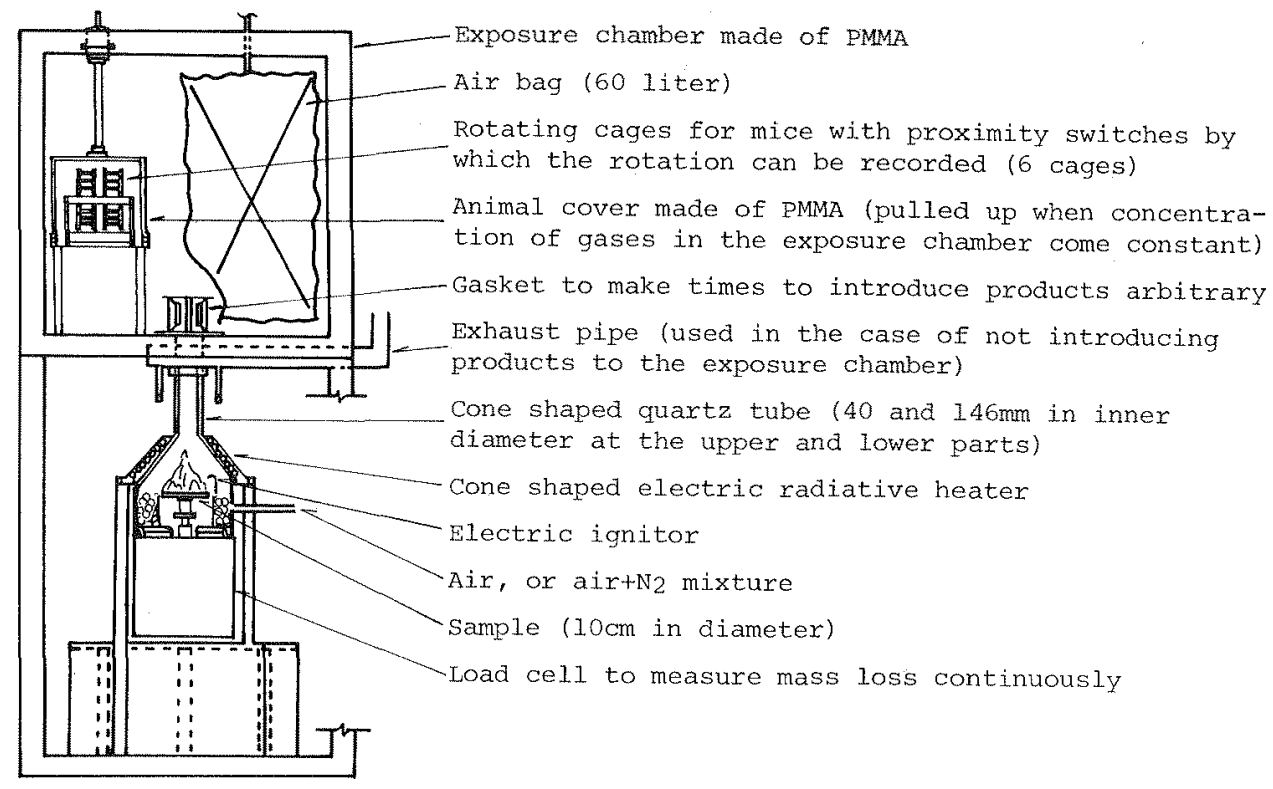

FIGURE 5. Toxicity test apparatus developed at Builaing Research Institute.

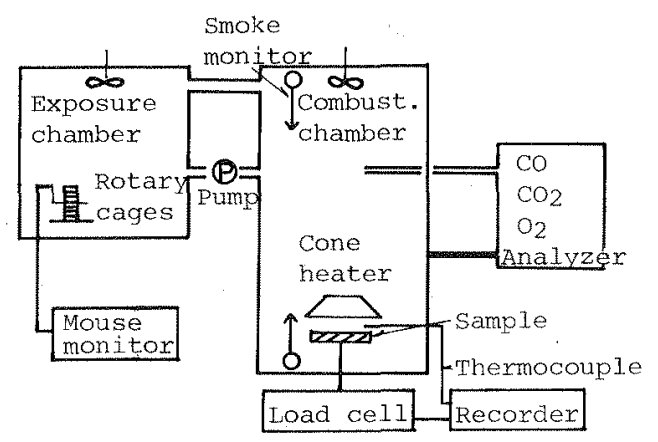

FIGURE 6. Toxicity test apparatus at Research Institute for Polymers and Iextiles.

\section{Toxicity Evaluation of Fire Effluents}

The research in Japan on toxicities of fire effluents from materials, broady deviced, consists of that based on the surface area of the material heated and that based on weight. In case of the former, research based on Ministry of Construction Proclamation 1231, the test method prescribed for control of fire-retardant materials used in high-rise buildings in Japan, is main. In this method, the material is burned in a furnace which is a modified version of the fire propagation test apparatus in Part 6 of BS 476 , and the time of incapaciation of a mouse is compared with that using wood (red lauan) which is the reference materials. In the latter, it is aimed to discern the toxicity par unit weight of material burned. There are versions such as a method with the volume of the test animal exposure chamber as 


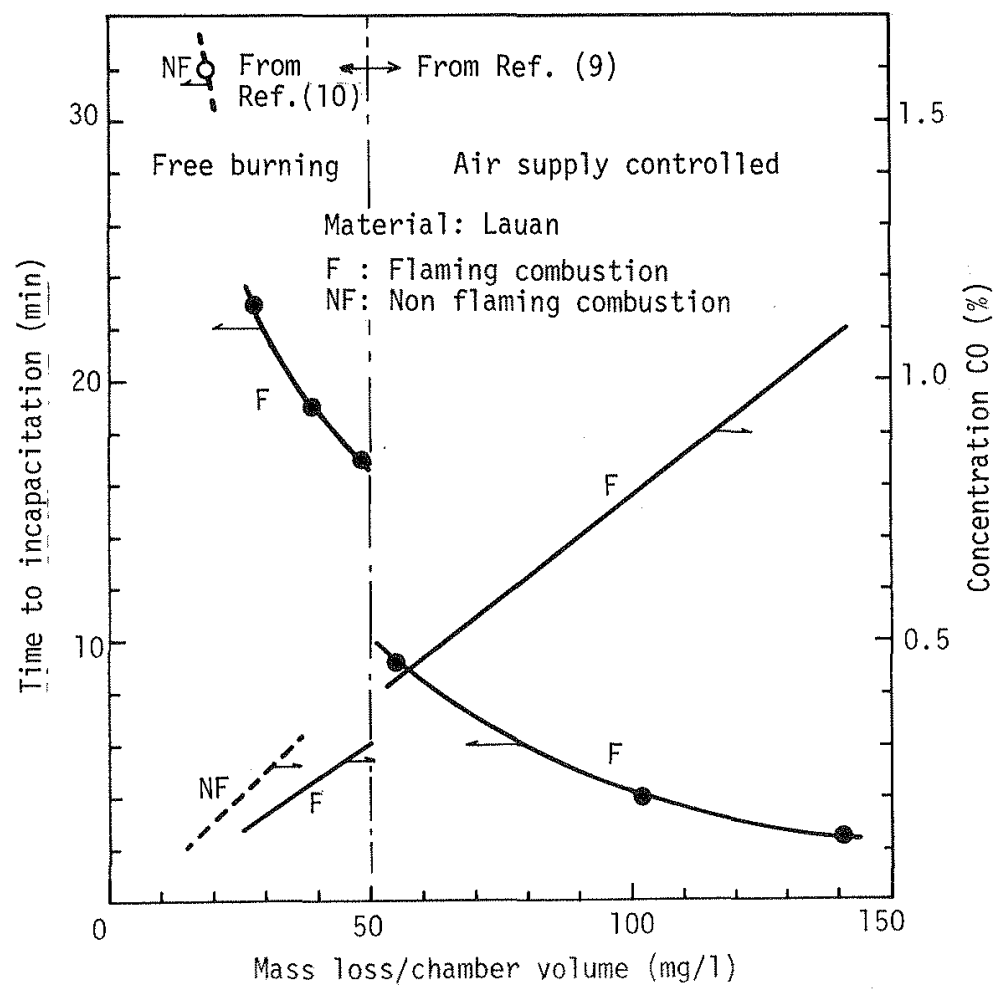

FIGURE 7. Animal test results for lauan at Building Research Institute and Research Institute for Polymers and Textiles.

the variable(5), a method with quantity of material varied(6), and a method with exposure time constant $(7)$.

Two new type of test apparatus are presently under development in Project Research. One is an apparatus with which partial pressure of oxygen and air supply volume are variable(8)(9) (Fig. 5), while the other is a closed type with $\mathrm{O}_{2}$ concentration in the combustion chamber variable(10)(Fig. 6). Both use cone-type furnaces and continuous mass loss measurements by losd cell and the andmals can be subjected to square wave exposure to combustion products in both methods.

With regard to the animal exposure experiments, the results obtained with the two test apparatus so far on the same material (lavan) are shown in Fig. 7. The experiments of the former method (right part of the Tig. 7) were carried out under the conditions of $2.5 \mathrm{~W} / \mathrm{cm}^{2}$ of heat flux, $4.61 / \mathrm{sec} / \mathrm{cm}^{2}$ of supplying air flow rate in flaming mode, and with the latter method (left part of the figure), the conditions were $2.0 \mathrm{~W} / \mathrm{cm}^{2}$ for smoldering, and $4.2 \mathrm{~W} / \mathrm{cm}^{2}$ for flaming. As co evolution depends on burning condtion (in this case controlled air supply rate or free burning), times to incapacitation of mice are different for the two method. However, it needs further study for lower range of the mass loading less than 50 $\mathrm{mg} / \mathrm{I}$ in the former method. It is planned to accumulate more detailed data hereafter varying the different parameters. 


\section{CONCLUSTON}

As mentioned at the beginning of the paper, studies on toxicities of fire effluents in Japan have in the past been carried out on relatively individual bases; however, with the initiation of Project Research, cooperated in by the United States and Canada, studies recently are in a more systematic manner. The number of researchers to cope with the problems that must be solved is still extremely small. Delay in resolving the problem of fire effluent toxicity means that many more human lives will be lost, with lack of more paper control of materials. It will be necessary for a systematically stronger research organization, including a setup for international research, to be established to achieve further advances in this field of study.

\section{REFTRENCES}

1. Tanaka, T., Nakaya, I., Yoshida, M.: "Full scale experiments for determing the burning condition to be applied to toxicity test," in the Paper to be present at the first international symposium on fire safety science, Nat. Bur. Stand. Gaithersburg, MD, 1985.

2. Kishitani, K., Nakamura, K.: "Research on evaluation of toxicities of combustion gases generated during Pires," in Proceedings of $3 \mathrm{rd}$ Joint Conference of UJNR Fire Research and Safety, NBS SP 540, 485-519, 1978.

3. Sakurai, T.: "Toxic gas test by the several pure and mixture gases," 3rd conference of Cenada-Japan-USA Trilateral Study Group on Fire Gas Toxicity, NRCC, Ottawa, Canada, Paper 20, 1984.

4. Saito, F.: Unpublished data arranged from "Factors accelerating the gas toxicity in a fire," in Proceeding of 3xd Joint Conference of UJNR Fire Research and safety, NBS SP 540, 528-548, 1978 .

5. Saito, F.: "Evaluation of toxicity of combustion products," in J. Comb. Tox. Vol. 4, p. 32, 1977.

6. Kishitani, K., Yusa, S.: "Study on evaluation of relative toxicities of combustion products of various materials," in J. Fac. Univ. of Tokyo (B), Vol. 35, No. 1, 1979.

7. Report on the Fire Prevention Systems for Rolling Stocks, Japan Association of Rolling Stock Industries; March 1978 (in Japanese).

8. Yusa, S.: "Development of laboratory test apparatus for evaluation of toxicity of combustion products of materials in fire." in Proceedings of 7 th Joint Panel Meeting of the UJNR Panel on Fire Research and Safety, NBSIR 85-3118, $472-487,1985$.

9. Yusa, S.: "Animal exposure test by new apparatus," 3rd Conference of Canada -Japan-USA Trilateral Cooperative Study on Fire Gas Toxicity, NRCC, Ottawa, Canada, Paper 13, 1984.

10. Furuya, M.: "Combustion condition of plastic materials and evaluation of toxicity of combustion products," 3rd Conference of Canada-Japan-USA Tri.lateral Cooperative Study on Fire Gas Toxicity, NRCC, Ottawa, Canada, Paper 14, 1984. 
